\title{
Rho Regulates Membrane Transport in the Endocytic Pathway to Control Plasma Membrane Specialization in Oligodendroglial Cells
}

\author{
Angelika Kippert, ${ }^{1,2 \star}$ Katarina Trajkovic, ${ }^{1,2 \star}$ Lawrence Rajendran, ${ }^{4}$ Jonas Ries, ${ }^{3}$ and Mikael Simons ${ }^{1,2}$ \\ ${ }^{1}$ Centre for Biochemistry and Molecular Cell Biology, University of Göttingen, 37073 Göttingen, Germany, ${ }^{2}$ Max-Planck-Institute for Experimental \\ Medicine, 37075 Göttingen, Germany, ${ }^{3}$ Technical University of Dresden, 01062 Dresden, Germany, and ${ }^{4}$ Max-Planck-Institute of Molecular Cell Biology and \\ Genetics, 01307 Dresden, Germany
}

\begin{abstract}
Differentiation of oligodendrocytes is associated with dramatic changes in plasma membrane structure, culminating in the formation of myelin membrane sheaths. Previous results have provided evidence that regulation of endocytosis may represent a mechanism to control myelin membrane growth. Immature oligodendrocytes have a high rate of clathrin-independent endocytosis for the transport of membrane to late endosomes/lysosomes (LE/Ls). After maturation and receiving signals from neurons, endocytosis is reduced and transport of membrane from LE/Ls to the plasma membrane is triggered. Here, we show that changes in Rho GTPase activity are responsible for switching between these two modes of membrane transport. Strikingly, Rho inactivation did not only reduce the transport of cargo to $\mathrm{LE} / \mathrm{L}$ but also increased the dynamics of LE/L vesicles. Furthermore, we provide evidence that Rho inactivation results in the condensation of the plasma membrane in a polarized manner. In summary, our data reveal a novel role of Rho: to regulate the flow of membrane and to promote changes in cell surface structure and polarity in oligodendroglial cells. We suggest that Rho inactivation is required to trigger plasma membrane specialization in oligodendrocytes.
\end{abstract}

Key words: oligodendrocytes; neurons; myelin; Rho GTPases; endocytosis; late endosomes/lysosomes

\section{Introduction}

Differentiation of oligodendrocytes is an extreme example of cell specialization characterized by the outgrowth of an extensive amount of plasma membrane. This process leads to the generation of myelin and is associated with dramatic changes in plasma membrane structure and composition (Salzer, 2003; Sherman and Brophy, 2005). Although myelin is still continuous with the plasma membrane, its composition differs fundamentally from that of the membrane surrounding the cell body (Taylor et al., 2004; Debruin and Harauz, 2007; Gielen et al., 2006). Myelin has an exceptionally high content of lipids (70\% of dry weight), in particular galactosylceramide and cholesterol, and contains a small number of different proteins, which are in most cases mainly found in myelin. The major myelin proteins in compact myelin, the proteolipid proteins (PLP/DM20), are highly hydrophobic, cholesterol-interacting proteins (Milner et al., 1985; Simons et al., 2000). Intuitively, one would assume that the synthesis of myelin membrane proteins and lipids is turned on by

Received Nov. 13, 2006; revised Feb. 14, 2007; accepted Feb. 20, 2007.

This work was supported by the Deutsche Forschungsgemeinschaft (SFB 523). We thank G. Schulz for technical assistance and E. Papoucheva for help with the FRET analysis. We are grateful to M. Matsuda, A. Benmerah, S. Schmid, S. Gutkind, and G. Superti-Furga for providing reagents.

${ }^{*}$ A.K. and K.T. contributed equally to this work.

Correspondence should be addressed to Dr. Mikael Simons, Centre for Biochemistry and Molecular Cell Biology, University of Göttingen, Humboldallee 23, 37073 Göttingen, Germany. E-mail: msimons@gwdg.de.

D0I:10.1523/JNEUROSCI.4926-06.2007

Copyright $\odot 2007$ Society for Neuroscience $\quad$ 0270-6474/07/273560-11\$15.00/0 neuronal signals, because they are required at the time oligodendrocytes begin wrapping their membrane around axons. Surprisingly, the gene expression of the major myelin components is initiated and also continues at a high rate in primary cultures of oligodendrocytes in the absence of neurons (Mirsky et al., 1980; Dubois-Dalcq et al., 1986; Dugas et al., 2006). However, because the ensheathment of axons must occur at the appropriate time of neuronal development, reciprocal communication between neurons and oligodendrocytes plays an important role in the coordination of myelin membrane growth (Barres and Raff, 1999; Edgar et al., 2004; Schafer and Rasband, 2006; Simons and Trajkovic, 2006). Recent work has provided evidence that myelin membrane trafficking is under the control of neuronal signals (Trajkovic et al., 2006). In the absence of neurons, PLP is internalized and stored in late endosomes/lysosomes (LE/Ls). After receiving an unknown diffusible neuronal factor, endocytosis of PLP is downregulated and transport of PLP from LE/L to the plasma membrane is triggered. The aim of the present work was to investigate the molecular mechanism of how oligodendrocytes switch between these two modes of membrane transport. We found that changes in Rho GTPase activity play a critical role in this process by regulating the flow of membrane through the endosomal system.

\section{Materials and Methods}

Antibodies and plasmids. The following plasmids were used: mutant and wild-type cDNAs of green fluorescent protein (GFP)-Eps15 (A. Benmerah, Institut Pasteur, Paris, France), mutant and wild-type GFP- 
dynaminII (S. Schmid, Scripps Research Institute, La Jolla, CA), RaichuRhoA-1237X (M. Matsuda, Kyoto University, Kyoto, Japan) (Yoshizaki et al., 2003), wild-type and mutant RhoA, RhoB, and RhoC (obtained from the Unité Mixte de Recherche cDNA Resource Centre), wild-type and mutant c-Src (G. Superti-Furga, EMBL, Heidelberg, Germany; S. Gutkind, National Institutes of Health, Bethesda, MD) (Sandilands et al., 2004); the N-terminal 20 amino acids of neuromodulin (which contain a consensus sequence for dual palmitoylation) fused to GFP (membranetargeted GFP) (Schneider et al., 2005). The following primary antibodies were used: hemagglutinin (HA) (16B12, mouse monoclonal; Covance, Berkley, CA), HA (rabbit polyclonal IgG; Abcam, Cambridge, UK), GFP (polyclonal rabbit; Abcam), GM130 (mouse monoclonal IgG1; BD Biosciences, Franklin Lakes, NJ), Lamp-1 (CD 107a, rat monoclonal; BD Biosciences), myc (rabbit polyclonal IgG; Upstate Biotechnology, Temecula, CA), myc (monoclonal IgG; Cell Signaling Technology, Denver, CO), O10 (monoclonal mouse IgM) (Jung et al., 1996), RhoA (26C4, mouse monoclonal; Santa Cruz Biotechnology, Santa Cruz, CA), and Src (36D10, rabbit monoclonal IgG; Cell Signaling Technology). Secondary antibodies were purchased from Dianova (Hamburg, Germany).

Cell culture, cloning, and transfections. Primary cultures of mouse oligodendrocytes were prepared as described previously (Simons et al., 2000). After shaking, cells were plated in MEM containing B27 supplement, 1\% horse serum (HS), L-thyroxine, tri-iodo-thyronine, glucose, glutamine, gentamycine, pyruvate, and bicarbonate on poly-L-lysinecoated dishes or glass coverslips. The oligodendroglial precursor cell line, Oli-neu, was cultured as described previously (Jung et al., 1995). For all experiments, Oli-neu cells with a low passage number were used. Primary cultures enriched in neurons were obtained by preparing a mixed brain culture from 16-d-old fetal mice. The cells were plated at a density of $\sim 200000$ cells $/ \mathrm{cm}^{2}$ and grown for 2 weeks in Sato-B27/1\% HS. The culture was enriched in neurons but contained some astrocytes. Conditioned neuronal medium was obtained from these cultures, collected after culturing for 2 weeks, centrifuged for $5 \mathrm{~min}$ at $4000 \times \mathrm{g}$, and used directly.

Primary cultures of astrocytes were prepared from a mixed brain culture from 16-d-old fetal mice. The cells were plated on uncoated cell culture dishes and cultured in DMEM/10\% HS.

Cells were trypsinized and transferred to a new dish to remove the neurons. Cultures that were highly enriched in astrocytes were grown for 2 weeks in Sato-B27/1\% HS.

Transient transfections were performed using FuGENE transfection reagent according to the manufacturer protocol. Immunofluorescence was performed as described previously (Trajkovic et al., 2006). For delivery of recombinant C3 transferase (Cytoskeleton, Denver, CO), Chariot reagent (Active Motif, Carlsbad, CA) was used according to the manufacturer protocol.

Wild-type, dominant-negative, and constitutively active RhoBenhanced GFP (EGFP) and RhoC-EGFP fusion products were generated from the respective HA-tagged Rho constructs by cloning them into the pEGFP-C1 vector (Clontech, Mountain View, CA) using the ApaI-KpnI site.

Immunofluorescence and endocytosis assays. Endocytosis was assessed by incubating Oli-neu cells stably expressing PLP-EGFP cells for $30 \mathrm{~min}$ with Transferrin-Rhodamine (Tf) (Invitrogen, Carlsbad, CA) or Dextran-Rhodamine 10K (Dextran) (Invitrogen). Cells were subsequently washed and fixed, followed by microscopy analysis. For assaying endocytosis of glycosylphosphatidylinositol (GPI)-cyan fluorescent protein (CFP), living cells were incubated with anti-GFP antibody in medium for $30 \mathrm{~min}$ at $4^{\circ} \mathrm{C}$, washed, incubated in medium at $37^{\circ} \mathrm{C}$ for 30 $\mathrm{min}$, and fixed. Fixed, nonpermeabilized cells were labeled with Cy5conjugated secondary antibodies to visualize GPI-CFP at the cell surface and then permeabilized and labeled with Cy3-conjugated secondary antibodies to resolve internalized protein. To analyze endocytosis of $\mathrm{ChxB}$, ChxB conjugated to FITC was bound to the cell surface at $4^{\circ} \mathrm{C}$, and the cells were warmed for $40 \mathrm{~min}$ to allow transport to the Golgi complex. Using mask overlay image analysis, we quantified the internalization of FITC-ChxB (Sigma-Aldrich, Deisenhofen, Germany) to the GM130positive Golgi apparatus. Laurdan (6-dodecanoyl-2-dimethylaminonaphtalene; Invitrogen) labeling was performed in live cultures ( $5 \mu \mathrm{M}, 30$ min at $37^{\circ} \mathrm{C}$ ), followed by fixation with $4 \%$ paraformaldehyde. To deplete sphingolipids, $50 \mu \mathrm{m}$ Fumonisin B1 was added to Oli-neu cells every $24 \mathrm{~h}$ for $3 \mathrm{~d}$.

Microscopy and analysis. Fluorescence images were acquired on a Leica (Nussloch, Germany) DMRXA microscope or a Zeiss (Jena, Germany) LSM 510 confocal microscope with a $63 \times$ oil plan-apochromat objective [numerical aperture (NA), 1.4]. For live cell imaging, coverslips containing the cells were mounted in a live-cell imaging chamber and observed in low fluorescence imaging medium (HBSS; 10 mM HEPES, $1 \%$ horse serum, $\mathrm{pH} 7.4$ ) at $37^{\circ} \mathrm{C}$. Temperature was controlled by means of a Tempcontrol 37-2 digital system or a custom-built perfusion system. Time-lapse imaging was performed on a Zeiss LSM 510 confocal laserscanning microscope. Image processing and analysis was performed using Meta Imaging Series 6.1 software (Universal Imaging Corporation, West Chester, PA). Quantification of fluorescence intensities and of colocalization was performed as described previously (Trajkovic et al., 2006). Vesicle movement was analyzed by collecting images at $\sim 15 \mathrm{~s}$ intervals. Ten subsequent images were superimposed, and the first image of the time stack was subtracted from the resulting picture. The resulting subtraction is shown in green, and the first image is shown in red. Movement within the imaging period was quantified by determining the ratio of the intensity of green to red pixels [(integrated intensity of subtraction plus integrated intensity of first image)/integrated intensity of first image] (Wubbolts et al., 1996).

For flourescence resonance energy transfer (FRET) measurements, we used Raichu-RhoA-1237X (Yoshizaki et al., 2003), and FRET was detected by an increase in donor fluorescence after photobleaching of the acceptor on a confocal Leica microscope (TCS SP2 equipped with AOBS) as described previously (Fitzner et al., 2006). Image analysis of FRET data was performed using custom-written MATLAB routines.

For Laurdan experiments, we used a Zeiss LSM 510 confocal microscope with a $63 \times$ oil plan-apochromat objective (NA, 1.4; Zeiss) to excite at $364 \mathrm{~nm}$, and images were recorded simultaneously in the range of 400 to $450 \mathrm{~nm}$ and 470 to $530 \mathrm{~nm}$ for the two channels, respectively. For analysis of the Laurdan images, an average background was determined for each channel and subtracted from the intensity images, which were then converted into GP images with the generalized polarization (GP) defined by the following:

$$
\mathrm{GP}=\frac{I_{(400-450)}-I_{(470-530)}}{I_{(400-450)}+I_{(470-530)}},
$$

using software written in MATLAB (MathWorks, Natick, MA). Note that this definition of the GP depends on the setup used and allows monitoring relative changes of membrane order but cannot be compared directly to absolute values in the literature. To determine the GP values at the plasma membrane, regions of interest were selected randomly and the average GP, weighted in each pixel with the total Laurdan intensity $I(400-450)+I(470-530)$, was calculated therein (Gaus et al., 2006). Statistical differences were determined with Student's $t$ test.

Src kinase and RhoA activity measurements. Rho activity was measured by affinity precipitation of active (GTP-bound) Rho from cell lysates using a glutathione $S$-transferase (GST) fusion protein containing the Rho-binding domain of Rhotekin followed by detection with the respective antibody by immunoblotting as described previously (Ren et al., 1999).

To measure Src kinase activity, cell lysates were immunoprecipitated with anti-Src kinase antibody and subjected to a kinase assay by using an Src Assay kit (Upstate Biotechnology). The assay is based on the quantification of the phosphorylation of a synthetic Src substrate peptide (KVEKIGEGTYGVVK). The phosphorylated substrate is then separated from residual $\gamma-{ }^{32} \mathrm{P}$-ATP using p81 phosphocellulose paper, followed by the quantification with a scintillation counter.

For immunoblotting, cells were lysed and protein levels quantified using Bradford Reagent (Bio-Rad, Hercules, CA). The cell lysates were loaded on a gel, separated by SDS-PAGE, and transferred to nitrocellulose using standard protocols. 


\section{Results}

Subcellular localization of PLP is regulated by Rho GTPases and tyrosine kinases

As a cellular model, we used the oligodendroglial cell line, Oli-neu, stably expressing PLP-EGFP (Trajkovic et al., 2006). The advantage of this system is that cell differentiation can be triggered synchronously by adding conditioned medium from primary neuronal cultures to the cells. This treatment leads to the formation of a branching network of cellular processes. The morphological differentiation of Oli-neu cells is accompanied by a reorganization of membrane trafficking as shown by the redistribution of PLP from $\mathrm{LE} / \mathrm{L}$ to the cell surface. This response was not observed when Oli-neu cells were cultured with conditioned medium from primary cultures of astrocytes (Fig. 1). One aim of our present work was to identify the molecular mechanisms of this regulation. To this end, we screened the effect of a wide range of small molecules on the distribution of PLP-EGFP in Oli-neu cells. The tyrosine kinase inhibitor, Genistein, and the Rho-kinase (ROCK) inhibitor, Y27632, led to a redistribution of PLP from Lamp-1-positive LE/Ls to the surface of the plasma membrane (Fig. 1). ROCK kinases are regulated by Rho; we therefore transfected Oli-neu cells with the C3 transferase to block the activity of Rho. Inhibition of Rho led to a similar redistribution of PLP (Fig. 1). These results suggest that the activity of Rho may be involved in the regulation of membrane trafficking in oligodendrocytes.

\section{Neurons regulate RhoA GTPase activity} in oligodendroglial cells

To investigate a possible influence of neurons on RhoA activity in Oli-neu cells, we determined the activity of RhoA in Olineu cells, which were treated with conditioned medium from neuronal cultures or untreated. RhoA activity was measured by affinity precipitation of active (GTP-bound) Rho from cell lysates using a GST fusion protein containing the Rho-binding domain of Rhotekin (Ren et al., 1999). We found that the stimulation of Oli-neu cells with neuronal medium decreased the activity of RhoA (Fig. $2 \mathrm{~A}$ ). To obtain further support for a downregulation of RhoA activity after cell differentiation, we took advantage of a recently developed FRET-based biosensor for RhoA activity (Raichu-RhoA1237X) (Yoshizaki et al., 2003). Raichu-RhoA monitors the balance between guanine nucleotide exchange factors and GTPase activating proteins. The GTP-loading of Raichu-RhoA leads to the intramolecular binding of GTP-RhoA to the effector protein, Rho effector protein kinase $\mathrm{N}$ (PKN), and brings CFP in closer proximity to yellow fluorescent protein (YFP), thereby leading to an increase in FRET. FRET efficiency was measured by donor

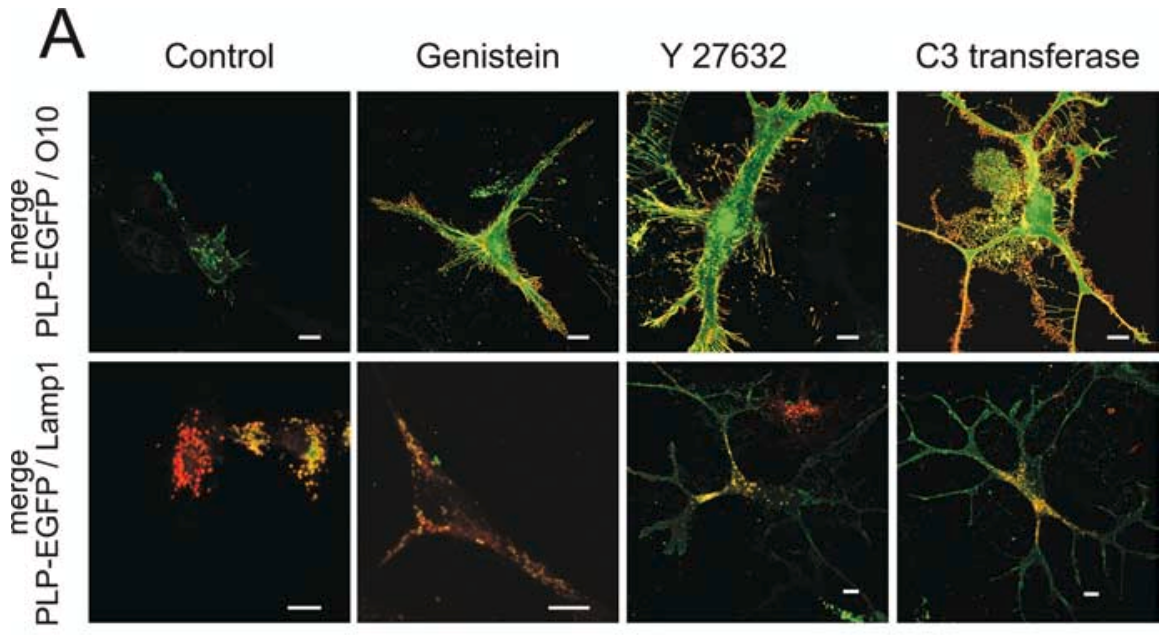

Figure 1. Subcellular localization of PLP is regulated by Rho GTPases and tyrosine kinases. Oli-neu cells stably expressing PLP-EGFP were treated for $16 \mathrm{~h}$ with Genistein, Y27632, C3 transferase, or conditioned medium from primary cultures of astroPLP on the cell surface (red) or by staining for Lamp-1 (red). Quantitative analysis of colocalization of PLP-EGFP with $010(\boldsymbol{B})$ and Lamp-1 (C) is shown. Values are given as the mean $\pm \mathrm{SE}\left(n>40\right.$ cells; ${ }^{*} p<0.05 ; t$ test). Scale bars, $10 \mu \mathrm{m}$.

dequenching after acceptor photobleaching. We found that coculturing Oli-neu cells with neurons or treatment of Oli-neu cells with conditioned neuronal medium reduced FRET efficiency compared with controls (Fig. $2 B$ ). These results with two independent approaches indicate that neurons reduce RhoA activity in oligodendroglial cells.

\section{Regulation of endocytosis by Rho GTPase and tyrosine} kinase activity

Internalization of plasma membrane can occur by different endocytic pathways, and several of those depend on the activity of Rho GTPases. We have shown previously that neurons reduce the endocytosis of PLP in oligodendrocytes (Trajkovic et al., 2006). We now determine whether the inhibition of endocytosis was specific for this particular pathway and, if so, how this pathway was regulated. To gain more insight in the regulation of endocy- 
A

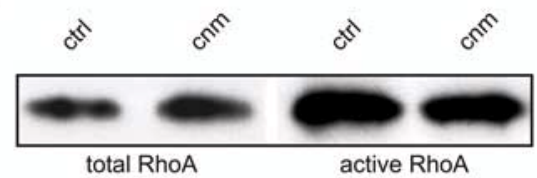

B

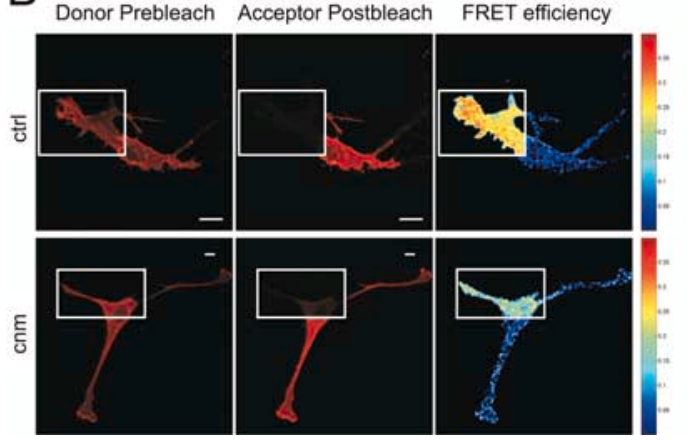

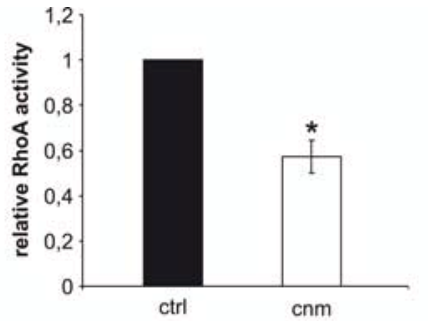

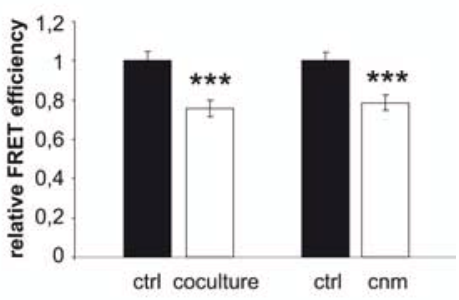

Figure 2. Neurons regulate RhoA GTPase activity in Oli-neu cells. $A, 0$ li-neu cells were grown for $\sim 8 \mathrm{~h}$ in the presence (cnm) or absence (ctrl) of conditioned medium from neuronal cultures. RhoA activity was measured by affinity precipitation of active (GTP-bound) Rho from cell lysates using a GST fusion protein containing the Rho-binding domain of Rhotekin. Precipitated proteins (active) and cell lysates (total) were immunoblotted with monoclonal antibody recognizing RhoA. Values are given as the mean \pm SE of an average of three independent experiments ( ${ }^{*} p<0.05 ; t$ test). $\boldsymbol{B}, 0$ li-neu cells were transfected with a plasmid encoding for Raichu-RhoA-1237X and grown for $\sim 8 \mathrm{~h}$ in the presence ( $\mathrm{cnm}$ ) or absence (ctrl) of conditioned medium from neuronal cultures or were added directly to primary neuronal cultures (coculture). Confocal fluorescence images of transfected Oli-neu cells are shown before (prebleach) and after (postbleach) photobleaching of the donor and acceptor, respectively. The acceptor was bleached in the region indicated by the rectangle. FRET efficiency was measured by donor dequenching after acceptor photobleaching and is represented in an efficiency map in pseudocolor (low to high FRET efficiency from blue to red). The error bars represent the means \pm SE $\left(n>25\right.$ cells; $^{* * *} p<0.001 ; t$ test). Scale bars, $10 \mu \mathrm{m}$

tosis in oligodendroglial cells, we started our analysis by examining receptor-mediated, clathrin-dependent, and fluid-phase endocytosis. Receptor-mediated, clathrin-dependent endocytosis was assessed by incubating Oli-neu cells for $30 \mathrm{~min}$ with Tf. Similar amounts of Tf were internalized in Oli-neu cells cultured with or without conditioned neuronal medium (Fig. 3). Subsequently, fluid-phase endocytosis was studied by feeding cells for $30 \mathrm{~min}$ with Dextran. Stimulation of Oli-neu cells by neuronal medium greatly inhibited the internalization of Dextran (Fig. 3). To examine by which pathway fluid-phase was taken up by oligodendroglial cells, we treated cells with various pharmacological inhibitors or expressed dominant-negative proteins to specifically interfere with the different endocytosis pathways. To inhibit clathrin-dependent internalization, we expressed a dominantnegative isoform of eps15 (EDelta/295) or dynaminII (dyn2K44A). Uptake of Dextran was not changed, although internalization of $\mathrm{Tf}$ was dramatically reduced (Fig. 3). These results indicated that fluid-phase did not depend on clathrin or dynaminII for endocytosis. Because most clathrin-independent pathways are sensitive to cholesterol or sphingolipid depletion, we used Fumonisin B1 (FB1) to selectively deplete sphingolipids (Cheng et al., 2006). Treatment of Oli-neu cells with FB1 did not affect the endocytosis of Tf but reduced the uptake of Dextran (Fig. 3). Both Rho GTPases and tyrosine kinases are known to play a regulatory role in clathrin-independent internalization pathways (Lamaze et al., 2001; Qualmann and Mellor, 2003; Damm et al., 2005). When Oli-neu cells were treated with the C3 transferase or Genistein, the uptake of Dextran was markedly reduced without affecting Tf internalization (Fig. 3).

To further explore the regulation of endocytosis, we studied the uptake of two lipid-raft markers, FITC-cholera toxin B sub- unit $(\mathrm{ChxB})$ and GPI-CFP. Both GPIanchored proteins and $\mathrm{ChxB}$ use clathrinindependent endocytosis pathways in most cells (Orlandi and Fishman, 1998; Sabharanjak et al., 2002; Kirkham et al. 2005). To analyze endocytosis of $\mathrm{ChxB}$ ChxB conjugated to FITC was bound to the cell surface at $4^{\circ} \mathrm{C}$, followed by incubation of the cells at $37^{\circ} \mathrm{C}$ for 40 min to allow transport to the Golgi complex. Using mask overlay image analysis, we quantified the internalization of FITC-ChxB to the GM130-positive Golgi apparatus. Compared with control cells, treatment with conditioned neuronal medium resulted in a significant inhibition in the delivery of FITC-ChxB to the Golgi (Fig. S1, available at www.jneurosci.org as supplemental material). To obtain further support for the inhibition of endocytosis by neuronal stimulation, we quantified the amount of FITC-ChxB being internalized during a $10 \mathrm{~min}$ uptake assay. Pretreatment of cells with conditioned neuronal medium reduced the uptake of $\mathrm{ChxB}$ significantly (Fig. S1, available at www.jneurosci.org as supplemental material). These findings support the conclusion that neurons regulate an endocytosis pathway used at least in part by ChxB. Next, we studied the endocytosis of GPI-CFP by performing antibody uptake experiments. In these experiments, internalized antibodies need to be distinguished from antibodies remaining at the cell surface. Because acidstripping and phosphatidylinositol-specific phospholipase C treatment were unable to fully remove anti-GFP antibody from the cell surface, we developed an alternative approach. Cells were labeled at $4^{\circ} \mathrm{C}$ with polyclonal antibodies against GFP (anti-GFP) and then warmed to $37^{\circ} \mathrm{C}$ to allow internalization of antibodies bound to GPI-CFP. Fixed, nonpermeabilized cells were labeled with Cy5-conjugated secondary antibodies to visualize GPI-CFP at the cell surface and then permeabilized and labeled with Cy3conjugated secondary antibodies to resolve internalized protein. Pretreatment of Oli-neu cells with neuronal medium led to a marked inhibition in endocytosis of GPI-CFP (Fig. $4 A$ ). In addition, and as observed for the uptake of Dextran, the treatment with Genistein and C3 transferase efficiently blocked endocytosis of GPI-CFP (Fig. 4A). Together, these data show that differentiation of Oli-neu cells is accompanied by a downregulation of an endocytosis pathway, which is used by GPI-linked fluorescent proteins and is responsible for the uptake of a major fraction of the fluid-phase. This pathway does not depend on clathrin function but requires tyrosine kinases and Rho activity.

\section{Endocytosed GPI-CFP is transported to LE/L in Oli-neu cells} In most cells, GPI-anchored proteins are routed from early endosomes into recycling endosomes before returning to the plasma membrane (Sabharanjak et al., 2002). Surprisingly, we found that a fraction of GPI-EGFP was present in LAMP-1positive LE/Ls in Oli-neu cells (Fig. $4 B$ ) as described previously for baby hamster kidney cells (Fivaz et al., 2002). Little colocalization of GPI-EYFP and Lamp-1 was seen in Oli-neu cells treated with conditioned neuronal medium (Fig. $4 B$ ). We followed the 


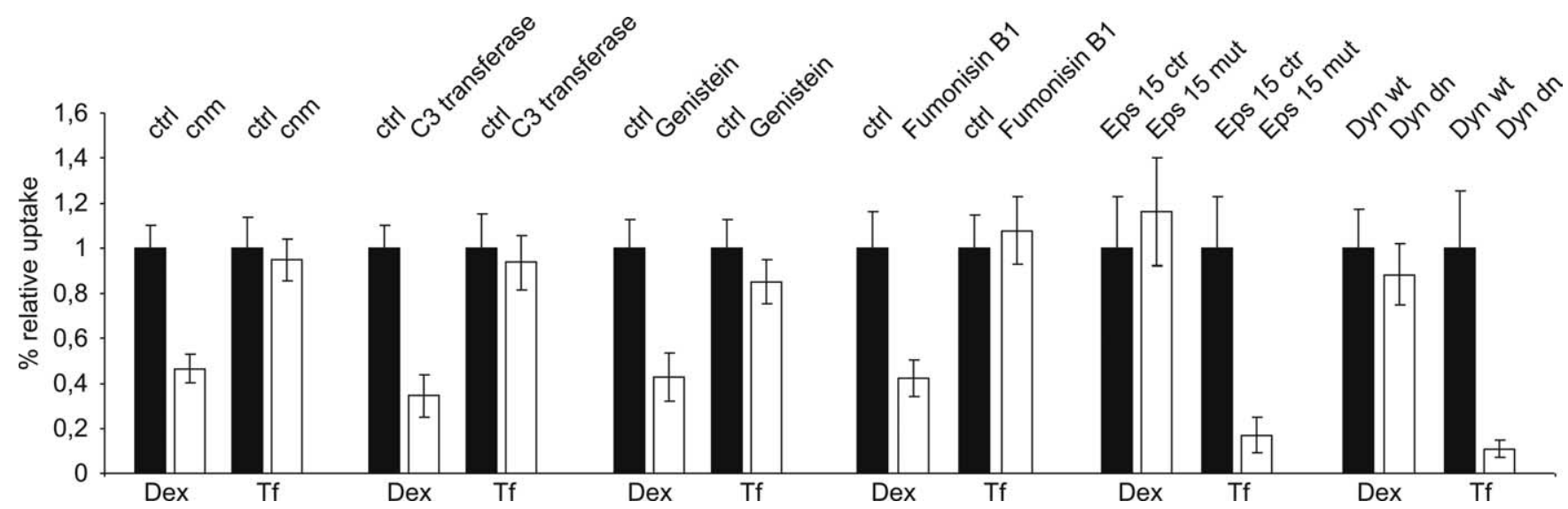

Figure 3. Regulation of clathrin-independent endocytosis by Rho GTPase and tyrosine kinase activity. Oli-neu cells were pretreated with Genistein (for $1 \mathrm{~h}$ ), $(3$ transferase (for $2 \mathrm{~h}$ ), conditioned neuronal medium (for 4 h), Fumonisin B1 (for 3 d), or transfected with plasmids encoding for Eps15III $\Delta 2$ (Eps15 ctrl), Eps15 E $\Delta 95 / 295$ (Eps15 mut), wild-type dynaminll (Dyn wt), or dominantnegative (K44A, Dyn dn). Receptor-mediated, clathrin-dependent endocytosis was assessed by incubating Oli-neu cells with Tf, and fluid-phase endocytosis was studied by feeding cells with Dextran-Rhodamine $10 \mathrm{~K}$ (Dex). Internalization $\left(30 \mathrm{~min}\right.$ at $37^{\circ} \mathrm{C}$ ) was quantified by image analysis. Values represent the means $\pm \mathrm{SE}(n>50$ cells).

endocytosis of GPI-CFP by antibody-internalization experiments and found that GPI-CFP was internalized from the plasma membrane to LE/Ls in Oli-neu cells (Fig. 4C).

\section{Regulation of LE/L dynamics by RhoB and c-Src activity}

We suggested previously that LE/Ls may have a specialized function in oligodendrocytes, namely to store and release membrane in a regulated manner (Trajkovic et al., 2006). Having established that Rho and tyrosine kinases regulate endocytosis in Oli-neu cells, we next asked whether they also regulate LE/L dynamics. In the absence of neurons, the majority of LE/Ls in oligodendrocytes are immobile and clustered perinuclear. When conditioned neuronal medium is added to Oli-neu cells, two pools of LE/Ls are observed: a perinuclear, immobile pool and a peripheral pool of highly mobile vesicles. When Oli-neu cells were treated with either C3 transferase or Genistein, we observed a redistribution of Lamp-1-positive LE/Ls to the cell periphery (Fig. 5A). To explore possible differences in the motility of LE/Ls, we performed fluorescence live imaging experiments by collecting images with a time interval of $15 \mathrm{~s}$ for PLP-EGFP and LysoTracker red. As shown previously, LE/Ls are primarily immobile in Oli-neu cells. Both treatments with Genistein or C3 transferase significantly increased the fraction of LE/Ls that moved during the time of the recordings (Fig. 5A). We investigated whether ROCK was involved in the regulation of LE/L motility by incubating cells with Y27632. We observed a significant increase in motility of LysoTracker-labeled vesicles (Fig. $5 B$ ). Similar results were obtained when primary cultures of oligodendrocytes were treated with Y27632 (Fig. 5C). These experiments suggest a role for Rho, ROCK, and tyrosine kinases in the regulation of LE/L dynamics in oligodendrocytes.

Higher vertebrates have three highly homologous Rho GTPases (RhoA, RhoB, and RhoC), which have different subcellular localizations and functions (Ridley, 2006). To test whether any of these proteins localizes to LE/Ls, we expressed HA-tagged wildtype, constitutively active and inactive versions of RhoA, RhoB, and RhoC, respectively. We found colocalization of both the wild-type and the constitutively active GTPase-deficient mutant (G14V) of RhoB with Lamp-1 (Fig. 5D). Predominantly cytoplasmic staining and some plasma membrane labeling, but no colocalization, with Lamp-1 was observed for RhoA and RhoC (data not shown). These results are consistent with previous stud- ies demonstrating a localization of RhoB to multivesicular endosomes (Robertson et al., 1995; Wherlock et al., 2004). We used a dominant-negative version of $\operatorname{RhoB}(\mathrm{T} 19 \mathrm{~N})$ to analyze whether RhoB is involved in the regulation of LE/L motility in Oli-neu cells. Transfection of dominant-negative RhoB led to a redistribution of a fraction of Lamp-1-positive LE/Ls to the cell periphery and increased the motility of the vesicles (Fig. $5 E$ ). To further confirm the role of RhoB in the regulation of endosome dynamics and to test for the specificity of the effects, we expressed the constitutively active forms of RhoA, RhoB, and RhoC in Oli-neu cells, in which the motility of endosomes had been induced by the incubation with conditioned neuronal medium. We found that all three Rho GTPases reduced the movement of LysoTrackerlabeled vesicles, but RhoB did this to the greatest extent (Fig. 5F). Because these results suggest a role for RhoB in the regulation of endosome dynamics, we measured the activity of RhoB in a Rhotekin pull-down assay after incubation of Oli-neu cells with conditioned neuronal medium. Similar to the results obtained with RhoA, we found that the levels of activated/GTP-bound RhoB decreased by conditioned neuronal medium compared with untreated cells (Fig. S2, available at www.jneurosci.org as supplemental material).

Recently, RhoB has been shown to regulate early endosome dynamics (Fernandez-Borja et al., 2005) and has been identified as a regulator of c-Src activity (Sandilands et al., 2004). We therefore tested the role of the tyrosine kinase, $\mathrm{c}-\mathrm{Src}$, in the regulation of LE/L dynamics. We began our analysis by determining the protein levels of Src in oligodendrocytes. We found that Oli-neu cells expressed Src and that levels of expression were reduced after treating cells for $16 \mathrm{~h}$ with conditioned neuronal medium (Fig. $6 A$ ). Next, we determined the c-Src kinase activity by phosphorylation of a specific c-Src peptide substrate. Conditioned neuronal medium reduced c-Src kinase activity compared with control cells, further suggesting a downregulation of Src function after treatment with conditioned neuronal medium (Fig. 6B)

We also detected Src in primary cultures of oligodendrocytes, and consistent with previous results (Colognato et al., 2004), the expression of Src was markedly reduced after morphological differentiation of oligodendrocytes (Fig. 6C).

We continued our analysis by determining the localization of c-Src in Oli-neu cells. Exogenously expressed active c-Src showed extensive colocalization with both PLP and Lamp-1, demonstrat- 

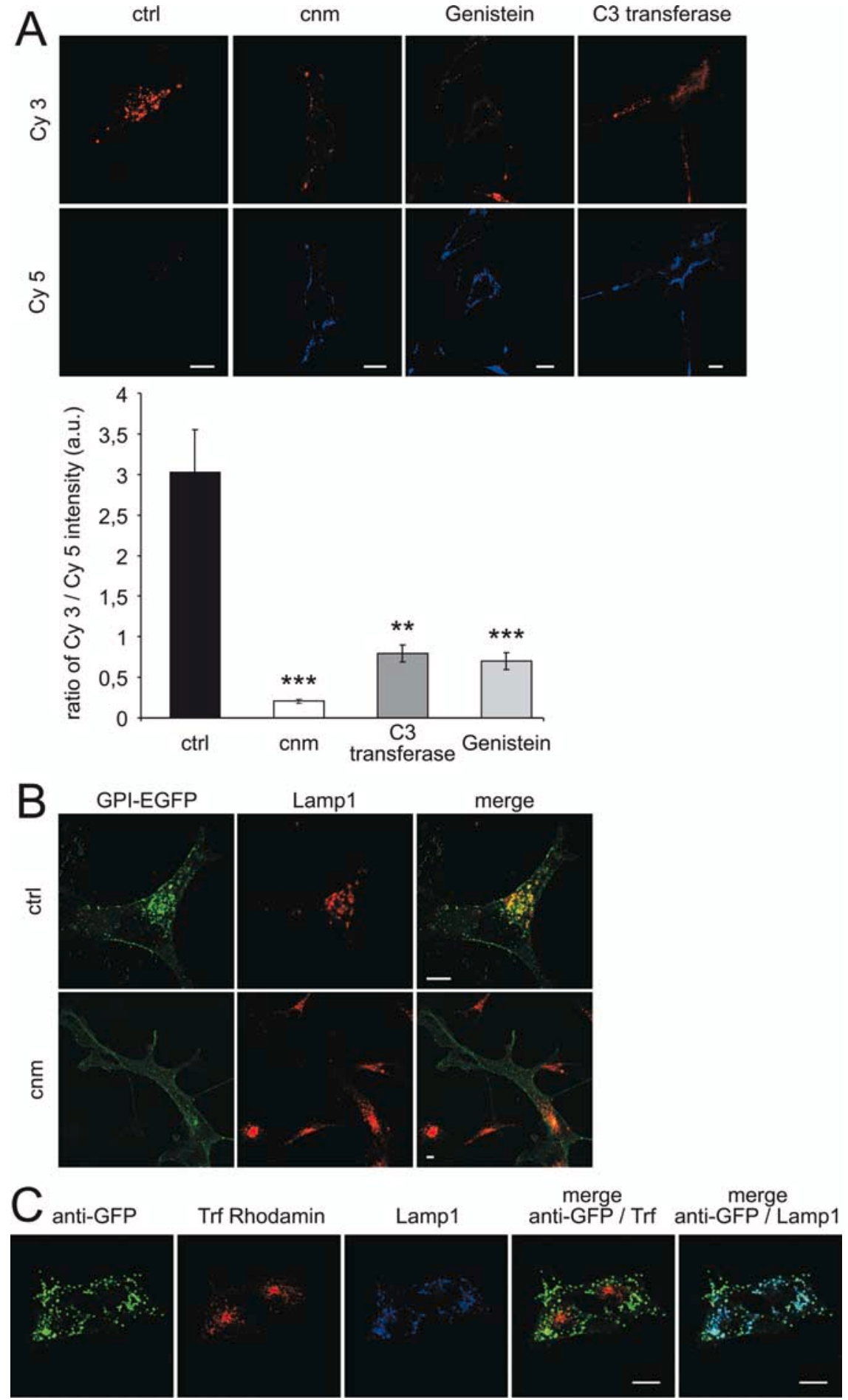

Figure 4. Neurons reduce the endocytosis of GPI-CFP to LE/Ls in Oli-neu cells. $\boldsymbol{A}$, Cells were treated with C3 transferase, Genistein, or conditioned neuronal medium ( $\mathrm{cnm}$ ) as indicated above (Fig. 3), and the uptake of GPI-CFP was analyzed by antibody uptake experiments. Cells were labeled at $4^{\circ} \mathrm{C}$ with a polyclonal antibody against GFP and then warmed to $37^{\circ} \mathrm{C}$ for 30 min to allow internalization of antibodies bound to GPI-CFP. Fixed, nonpermeabilized cells were labeled with Cy5-conjugated secondary antibody to visualize GPI-CFP at the cell surface (blue) and then permeabilized and labeled with Cy3-conjugated secondary antibodies to resolve internalized protein (red). By image analysis, we determined the ratio of Cy3- to Cy5-labeled GPI-CFP to obtain a value for the amount of protein internalized. Values represent the mean $\pm \mathrm{SE}\left(n>30\right.$ cells; ${ }^{* *} p<0.01 ;{ }^{* *} p<0.001 ; t$ test). $\boldsymbol{B}$; Oli-neu cells were transfected to express GPI-EGFP, incubated with conditioned neuronal medium (cnm) for 16 h or not incubated (ctrl), and treated with cycloheximid for the last $4 \mathrm{~h}$ of the incubation period to inhibit protein synthesis and to chase GPI-EGFP from the biosynthetic pathway. Cells were processed and analyzed by immunofluorescence for Lamp-1 (red) and GPI-EGFP (green) colocalization. C, The endocytosis of GPI-CFP was followed by antibody-internalization experiments (for $45 \mathrm{~min}$ at $37^{\circ} \mathrm{C}$ ). Cells were labeled at $4^{\circ} \mathrm{C}$ with polyclonal antibodies against GFP (anti-GFP) and then warmed to $37^{\circ} \mathrm{C}$ to allow internalization of antibodies bound to GPI-CFP together with Tf. Cells were fixed, permeabilized, and labeled with Alexa 488-conjugated secondary antibodies to resolve internalized GPI-CFP. Note the colocalization of anti-GFP (green) with Lamp-1 (blue) but not with Tf. Scale bars, $10 \mu \mathrm{m}$. ing its LE/L localization in Oli-neu cells (Fig. 6D). We expressed active c-Src in primary cultures of oligodendrocytes and observed the same extent of colocalization with Lamp-1. In addition, we found that exogenously expressed active c-Src resulted in perinuclear clustering of LE/Ls in primary oligodendrocytes (Fig. $6 E$ ), suggesting a role for $\mathrm{Src}$ in the regulation of LE/L function.

To determine whether Src influences the motility of LE/L, we exogenously expressed the constitutively active form of c-Src in Oli-neu cells, which had been preincubated with conditioned neuronal medium. Expression of constitutively active c-Src resulted in perinuclear clustering of LE/Ls and in a reduction of the motility of LysoTracker-labeled vesicles (Fig. 6F). Thus, both changes in Rho and Src activity modulate the dynamics of LE/Ls in Olineu cells.

\section{Plasma membrane condensation in Oli-neu cells}

Our results indicate that differentiation of Oli-neu cells is not only accompanied by a downregulation of a clathrinindependent, sphingolipid/cholesteroldependent endocytosis pathway, but is also associated with the mobilization of late endosomal/lysosomal membrane possibly for transport back to the plasma membrane. Both mechanisms may result in a gradual accumulation of cholesterol and sphingolipids in the plasma membrane of Oli-neu cells.

To study whether differentiation of Oli-neu cells is accompanied by alterations in the lipid structure of the plasma membrane, we used the fluorescent probe Laurdan to visualize its lipid order. Laurdan is an environmentally sensitive dye that undergoes a shift in its peak emission wavelength from $\sim 500 \mathrm{~nm}$ in fluid membranes to $\sim 440 \mathrm{~nm}$ in ordered membranes (Bagatolli et al., 2003; Gaus et al., 2003). The fluorescence intensity of Laurdan was recorded simultaneously at both peak emission wavelengths, and the normalized ratio representing the GP was used to determine the lipid order in the cell membranes. Higher GP values indicate a more condensed and ordered membrane. We found that treatment of Olineu cells with conditioned neuronal medium resulted in a dramatic increase in the lipid order of the cell membrane (Fig. $7 A, B)$. Furthermore, the GP images revealed that the membrane in the cellular processes was more condensed and ordered than the membrane enclosing the cell body (Fig. 7C). When Oli-neu cells 


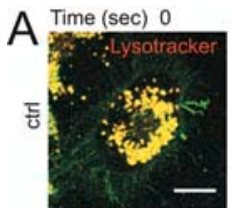

Time (sec) 0

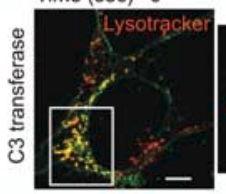

Time (sec) 0
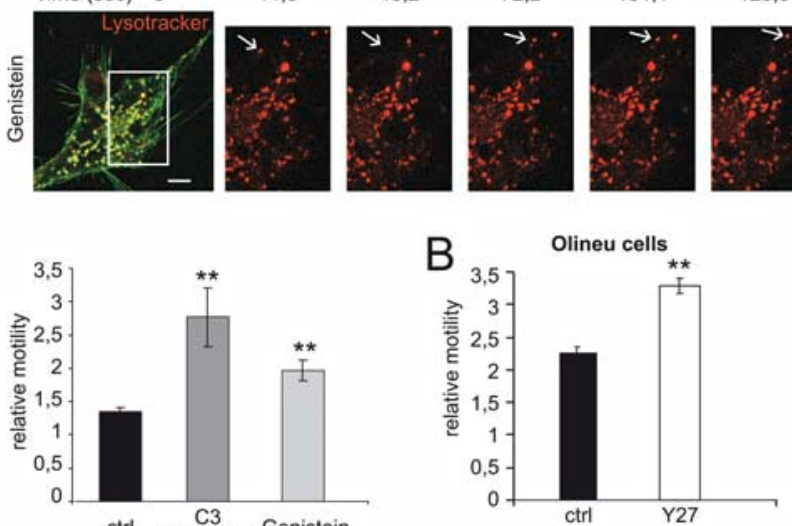

C primary oligodendrocytes

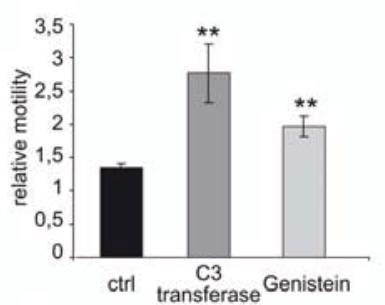

\section{PLP-EGFP}
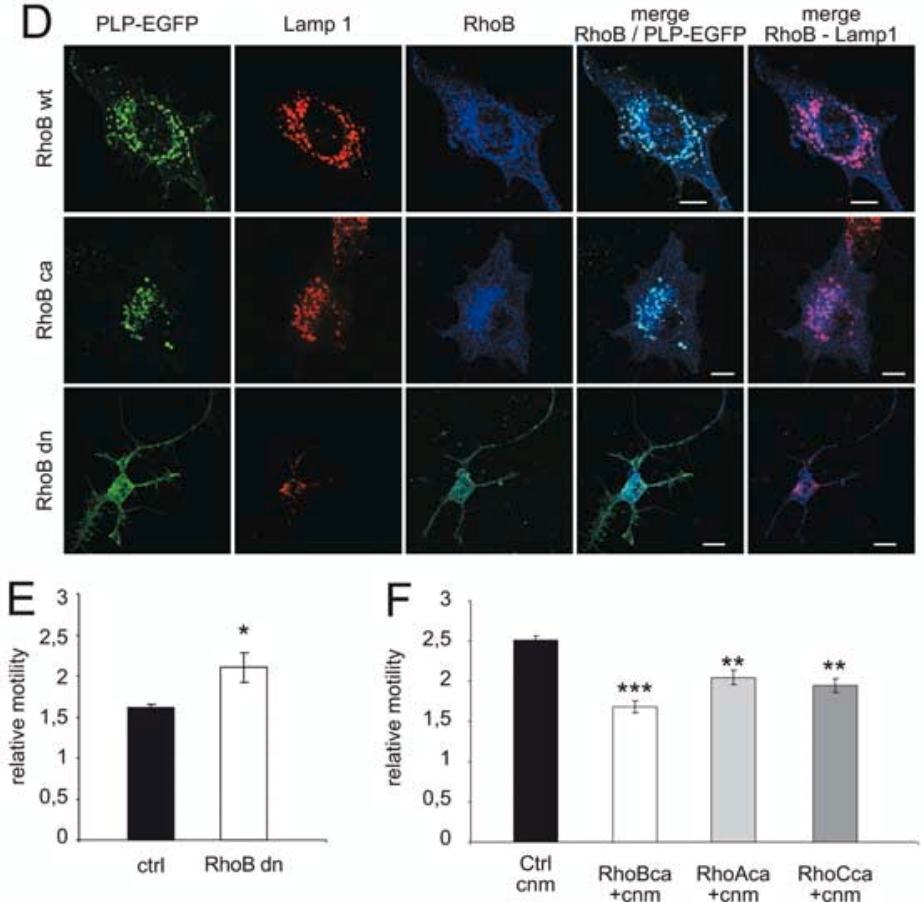

Figure 5. Regulation of LE/L dynamics by RhoB and tyrosine kinase activity. $\boldsymbol{A}$, Living Oli-neu cells expressing PLP-EGFP (green) were treated with C 3 transferase or Genistein, labeled with LysoTracker (red), and observed by confocal microscopy. Images were collected every $\sim 15 \mathrm{~s}$. A representative example of a time stack is shown. The images at the right of each time stack show a merged image (see Material and Methods) with the first image in red and movement over a $\sim 130$ s period in green. Relative motility of LE/Ls was quantified by determining the ratio of the integrated intensity of green to red pixels (see Material and Methods). Examples of moving vesicles are highlighted with arrows. Values represent the mean $\pm \mathrm{SE}\left(n>20\right.$ cells; ${ }^{* *} p<0.01$; $t$ test). $\boldsymbol{B}, \boldsymbol{C}$, Oli-neu cells $(\boldsymbol{B})$ and primary cultures of oligodendrocytes $(\boldsymbol{C})$ (for 2 d in culture) were pretreated with $10 \mu \mathrm{m} Y 27632$ for $2 \mathrm{~h}$ or left untreated, and the motility of LysoTracker-labeled vesicles was determined as in $\boldsymbol{A}$. Primary oligodendrocytes were identified by incubating living cells with 04 and Alexa 488-conjugated secondary antibody. Values represent the mean $\pm \mathrm{SE}(n>$ 20 cells; ${ }^{*} p<0.05 ;{ }^{* *} p<0.01 ; t$ test). D, Oli-neu cells were cotransfected to express PLP-EGFP and HA-tagged wild-type (wt), constitutively active (ca), and constitutively inactive ( $\mathrm{dn}$ ) versions of RhoB. Colocalization with PLP (green) and Lamp-1 (red) was observed for wild-type and the constitutively active versions of RhoB (blue). $\boldsymbol{E}$, Oli-neu cells were transfected to express membrane-targeted GFP (ctrl) or the dominant-negative version of RhoB (T19N) fused to GFP (RhoB dn), labeled with LysoTracker were treated with the C3 transferase, we also observed an increase in the GP values predominately in the membrane protrusions (Fig. $7 A, C$ ).

\section{Discussion}

We show that changes in Rho activity are responsible for switching between two modes of membrane transport in Oli-neu cells. In immature cells Rho is required for the function of a clathrin-independent endocytosis pathway that is used to transport membrane to LE/L. After morphological differentiation of Oli-neu cells, Rho activity is reduced, which is accompanied by the specific downregulation of the clathrin-independent endocytosis pathway and the mobilization of $\mathrm{LE} / \mathrm{L}$ vesicles.

What is the physiological function of this regulation? The formation of myelin requires the synthesis of a huge amount of membrane with a specific lipid composition. We therefore propose that the downregulation of this sphingolipid/ cholesterol-dependent endocytosis pathway represents a mechanism to control the plasma membrane composition of oligodendrocytes. This mechanism may contribute to the generation of myelin with its exceptionally high content of galactosylceramide and cholesterol. The reduction of this specific form of endocytosis may lead to a gradual accumulation of myelin membrane components within the plasma membrane of oligodendrocytes. Indeed, by using Laurdan to visualize the lipid packing, we observed a significant increase in the lipid order of the plasma membrane after treatment of the cells with conditioned neuronal medium or $\mathrm{C} 3$ transferase. We have shown recently that the formation of myelin in neuron-glia cocultures is associated with a condensation of the plasma membrane and that myelinbasic protein (MBP), a protein essential for myelin biogenesis, was involved in this process of membrane rearrangement (Fitzner et al., 2006). It is interesting that Oli-neu cells, which do not form compact myelin and only express small amounts of MBP, start to condense their membrane

\section{$\leftarrow$}

red, and imaged by confocal microscopy. Changes in mobility were determined as described in $\boldsymbol{A}$. Values represent the mean \pm SE ( $n>20$ cells; ${ }^{*} p<0.05 ; t$ test). $\boldsymbol{F}$, 0li-neu cells were transfected to express membrane-targeted GFP (ctrl) or the constitutively active versions of RhoB, RhoA, and RhoC fused to GFP treated with conditioned neuronal medium (cnm) for $12 \mathrm{~h}$ and labeled with LysoTracker red, and changes in mobility were determined as described in $A$. Values represent the mean \pm SE $\left(n>20\right.$ cells; ${ }^{* *} p<0.01 ;{ }^{* *} p<$ $0.001 ; t$ test). Scale bars, $10 \mu \mathrm{m}$. 
A

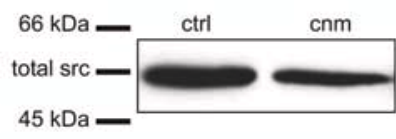

$\mathrm{C}_{+ \text {blocking pep }}^{\text {early pOL }}$

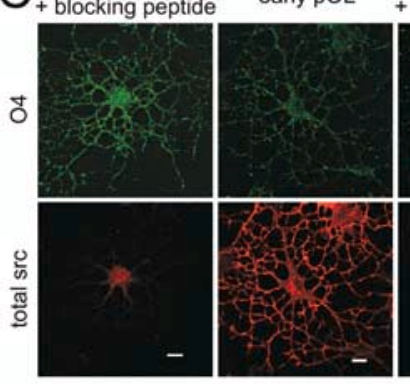

early pOL

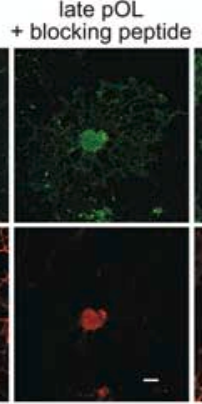

tide
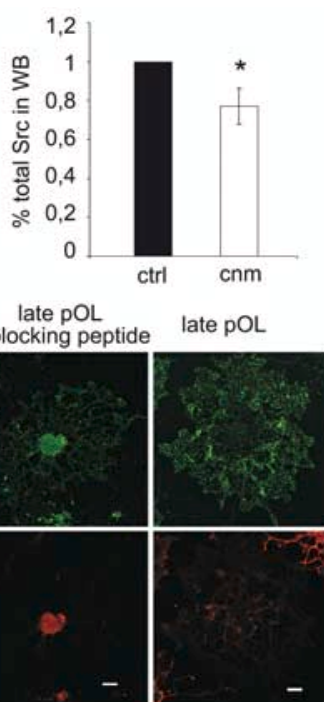

B
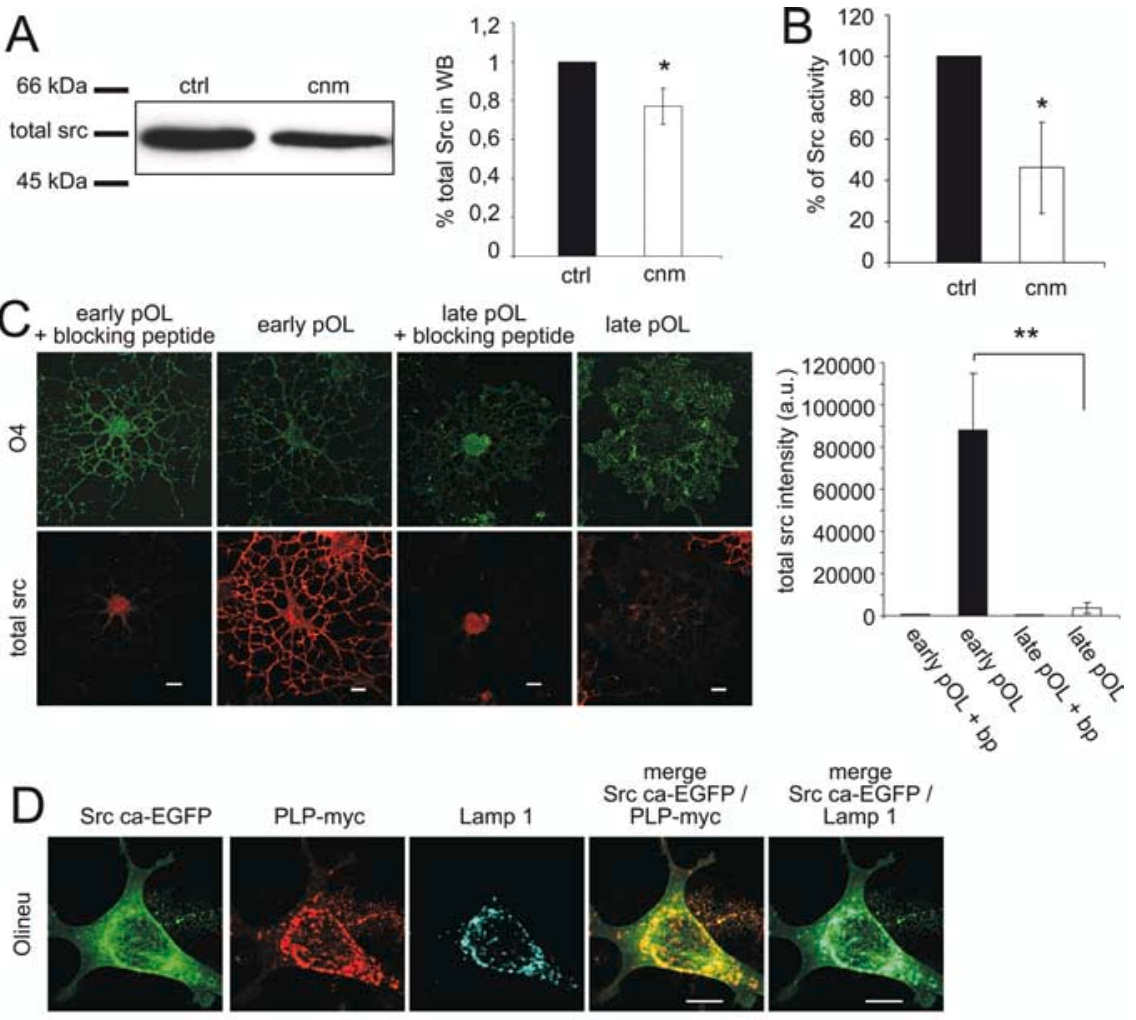

Lamp 1

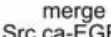

Src ca-EGFP/

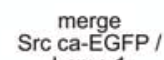

PLP-myc

Lamp 1
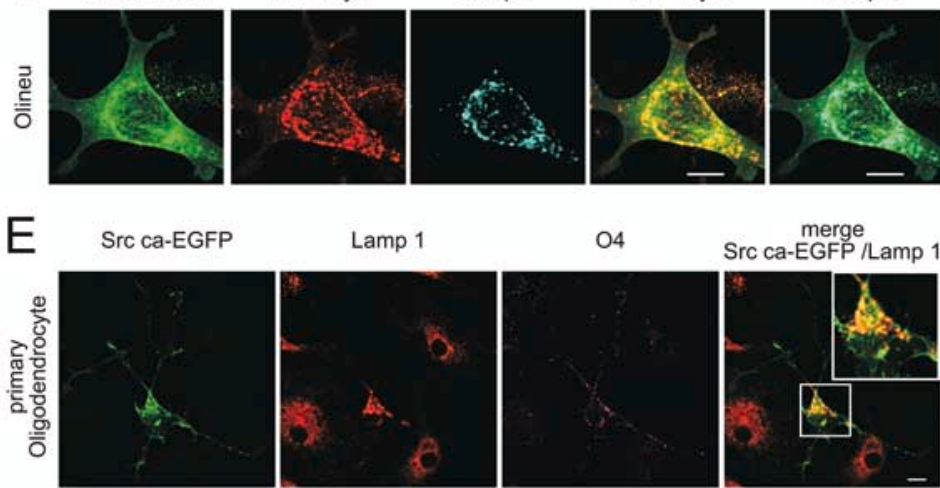

Lamp 1

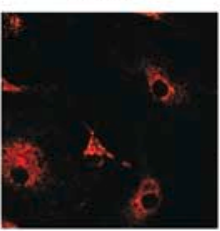

O4

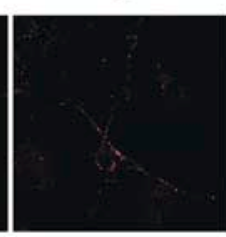
Src ca-EGFP /Lamp

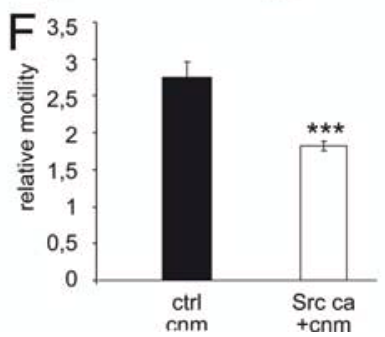

Figure 6. Changes in c-Src activity regulate the dynamics of LE/L. $A$, Oli-neu cells were incubated with conditioned neuronal medium (cnm) for $16 \mathrm{~h}$ or left untreated, cell lysates were prepared, and equal amounts of total protein were loaded and separated by SDS-PAGE. Src levels were determined by Western blot analysis. Values are presented as the mean \pm SD ( $n=4$ experiments; ${ }^{*} p<0.05$; $t$ test). $\boldsymbol{B}$, To determine the activity of $c-S r c$, Oli-neu cells were treated with conditioned neuronal medium or were untreated, and the cell lysates were immunoprecipitated with anti-Src antibodies and subjected to kinase assays. Results are expressed as the mean \pm SD of four experiments ( ${ }^{*} p<0.05 ; t$ test). C, Primary oligodendrocytes (p0L) were cultured for $2-5 \mathrm{~d}$, and levels of Src were determined at an early stage (cells with processes) and at a later stage of differentiation (cells with sheets) by quantifying immunofluorescence intensities. The specificity of the signal was demonstrated by preincubation with a blocking peptide (bp). Values are presented as the mean $\pm \mathrm{SE}\left(n>15\right.$ cells; ${ }^{* *} p<0.01 ; t$ test). $\boldsymbol{D}, 0$ li-neu cells were cotransfected with plasmids encoding for PLP-myc and constitutively active c-Src-EGFP (Src ca). E, Primary oligodendrocytes were transfected to express constitutively active c-Src-EGFP (Src ca). Immunofluorescence analysis reveals colocalization of c-Src-EGFP with Lamp-1. Note also the perinuclear clustering of LE/Ls. F, Oli-neu cells were transfected with membrane-targeted GFP (ctrl) or the constitutively active c-Src (Src ca), treated with conditioned neuronal medium, labeled with LysoTracker red, and imaged by confocal microscopy. Relative motility of LE/Ls was determined as described in Figure $3 A$. Values represent the mean $\pm S E(n>20$ cells; *** $p<0.001 ; t$ test). Scale bars, $10 \mu \mathrm{m}$.

after incubation with conditioned neuronal medium or Rho inactivation. The changes in membrane transport described in this study may contribute to the formation of condensed membrane domains in the plasma membrane of Oli-neu cells. Another, but not mutually exclusive, possibility is an increase in the biosynthesis of specific lipids and/or proteins after Rho inactivation or after receiving conditioned neuronal medium.

During development, oligodendrocytes regulate the composition as well as the size of their plasma membrane. Cells have, in general, a high rate of endocytosis. In fact, most cells internalize their entire cell surface within a few hours and keep a large fraction of their membrane in intracellular endosomal pools (Bomsel et al., 1989). In Oli-neu cells, the inactivation of Rho or the treatment with conditioned neuronal medium did not only reduce fluid-phase uptake but also increased the cell surface area. It is tempting to speculate that the regulation of cell size involves the balance between exocytosis and endocytosis. After differentiation, oligodendrocytes seem to shift this balance toward a high rate of exocytosis and a low rate of endocytosis, possibly to extend their surface, which eventually becomes $\sim 10,000$ times greater than that of a typical animal cell (Pfeiffer et al., 1993).

Previous work has shown that extracellular matrix components, such as laminin-2, promote extensive membrane extension in oligodendrocytes through integrin interactions (Buttery and ffrenchConstant, 1999; Chun et al., 2003; Colognato et al., 2004). The specific downregulation of a clathrin-independent endocytosis pathway by attachment to the extracellular matrix is interesting in this aspect (del Pozo et al., 2005). PLP, which forms a signaling complex with integrins in oligodendrocytes, may directly participate in the regulation of its own endocytosis by binding to the extracellular matrix (Gudz et al., 2002, 2006). Interestingly, a recent study shows that changes in the extracellular matrix regulate intracellular vesicular trafficking pathways in oligodendrocytes (Siskova et al., 2006).

The clathrin-independent endocytosis pathway that we identified in Oli-neu cells may be related to a previously described clathrin- and caveolin-independent pinocytic pathway (Sabharanjak et al., 2002) or to a closely related pathway implicated in the uptake of interleukin 2 receptors (Lamaze et al., 2001) and sodium pumps (Schmalzing et al., 1995). Because these pathways work constitutively and have a preference for specific lipids, they may have a very important role in the regulation of plasma membrane size and composition. The family of Rho GTPases are particularly well positioned to participate in this process of surface area homeostasis. Rho GTPases are able to respond to specific cues from the extracellular environment and 

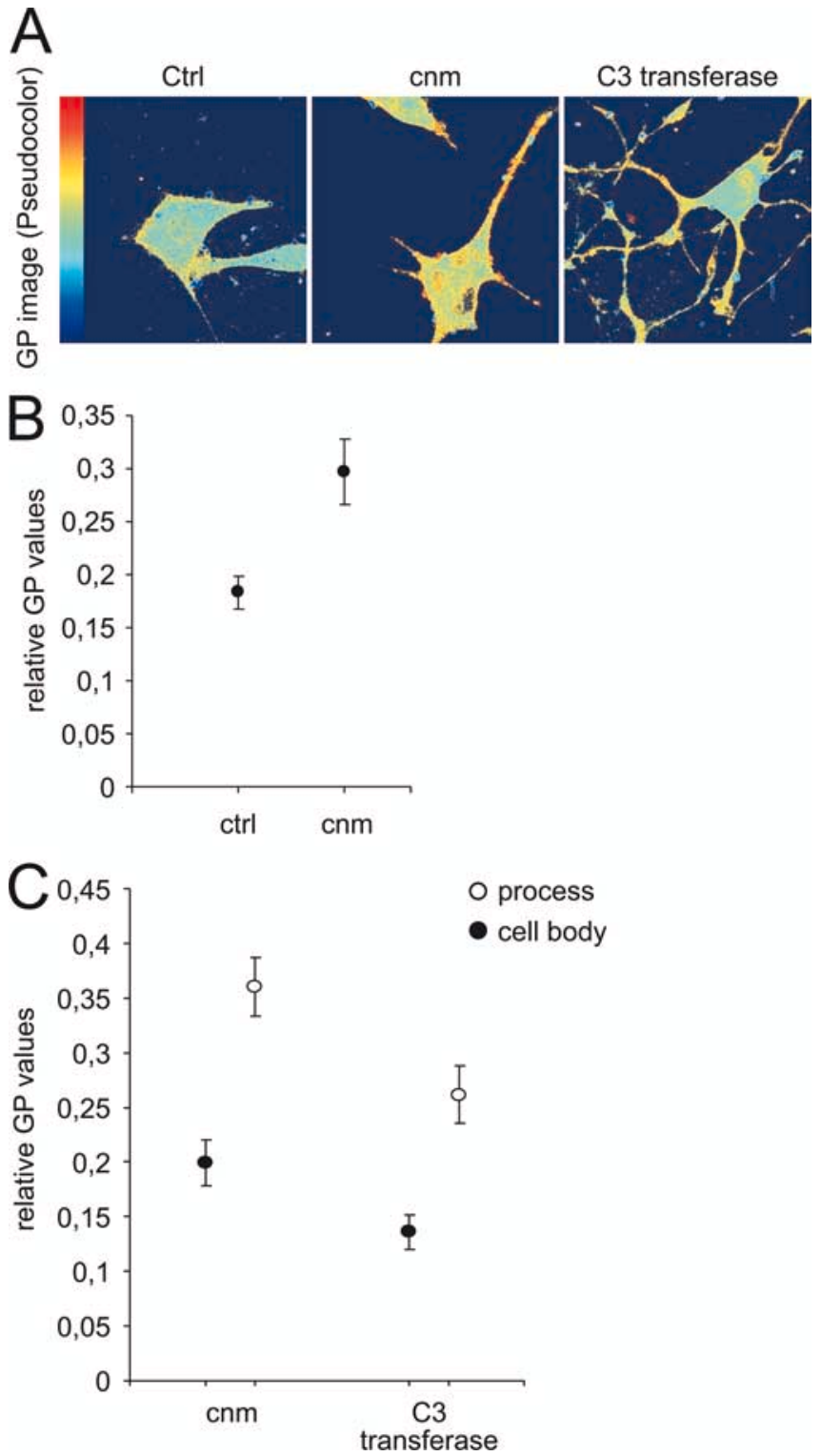

Figure 7. Neurons and RhoGTPase inactivation trigger plasma membrane condensation in Oli-neu cells. A, Oli-neu cells were left untreated (ctrl) or treated with (3 transferase or conditioned neuronal medium (cnm) for $16 \mathrm{~h}$, labeled with Laurdan, fixed, and processed for microscopy analysis. GP values were calculated from the Laurdan intensity images and pseudocolored as indicated (low to high GP values from blue to red). $\boldsymbol{B}$, GP values at the cell borders (3-6 pixels) were measured ( $n>100$ values from $>15$ cells), and values were presented in the graph as the means $\pm 2 \mathrm{SE}(p<0.001)$. C, For cells treated with conditioned neuronal medium and $(3$ transferase, GP values were measured for the membrane in the processes and for membrane enclosing the cell body. The GP values differed significantly $(p<0.001)$, indicating a polarization of the cell surface.

to coordinate the cellular response by linking membrane with actin dynamics (Ridley, 2006).

It is interesting that Rho and tyrosine kinases not only regulated the transport of cargo to LE/Ls but also controlled the dynamics of LE/Ls. LE/Ls may have a specialized function in oligodendrocytes, namely to store and release membrane after request. The observations that a large fraction of PLP accumulates undegraded in LE/Ls (Simons et al., 2002; Trajkovic et al., 2006) and that degradation of PLP involves the proteasome system (Kramer-Albers et al., 2006; McLaughlin et al., 2006) are consistent with this function. We found that RhoB-dependent and c-Src-dependent signaling pathways are responsible for the mo- bilization of LE/Ls. A RhoD-hDia2C-Src signaling cascade has been shown previously to regulate early endosome dynamics, suggesting that different RhoGTPases use similar effectors to control the motility of distinct populations of endosomes (Gasman et al., 2003). Additional work will be required to determine whether the mobilization of LE/Ls to the plasma membrane by Rho inactivation triggers LE/L membrane exocytosis in oligodendrocytes. Interestingly, regulated exocytosis of LE/Ls has been implicated recently in the regulation of process outgrowth and arborization in neurons (Arantes and Andrews, 2006).

Our results stress the important role of Rho in vesicular trafficking and demonstrate how changes in Rho activity can induce a switch between two modes of membrane transport. This work, together with previous studies, suggests that Rho inactivation is a critical factor to initiate the growth of myelin membrane in oligodendrocytes (Liang et al., 2004; Mi et al., 2005). Signaling from integrins to Fyn and Rho may play a critical role in the regulation of this pathway (Osterhout et al., 1999; Wolf et al., 2001; Liang et al., 2004). In contrast, the activity of other Rho GTPases, Cdc42 and Racl, seems to increase as differentiation proceeds, and recent evidence suggests that its activity is required to regulate a late stage in myelin formation (Liang et al., 2004; Thurnherr et al., 2006). Interestingly, in Schwann cells of the peripheral nervous system, the Rho-ROCK pathway is not inactivated during myelination as in oligodendrocytes (Melendez-Vasquez et al., 2001). Instead, it is switched on in Schwann cell microvilli, where it seems to play an important role in regulating the myelination of peripheral nerves (Gatto et al., 2003; Melendez-Vasquez et al., 2004). It will now be important to determine how the Rho GTPases are regulated and to identify the neuronal signals that reduce Rho activity in oligodendrocytes.

It is intriguing that neurons and oligodendrocytes seem to use Rho-kinase-dependent mechanisms for bidirectional communication. It is well known that many oligodendrocyte-derived inhibitors limit axonal regeneration by activating a RhoA signaling pathway in neurons (Yiu and $\mathrm{He}, 2006$ ). Likewise, it is feasible that Rho is turned on in oligodendroglial cells in diseases such as multiple sclerosis, in which the differentiation of oligodendrocytes is blocked in the vicinity of demyelinating lesions. Therefore, more knowledge in the regulation of Rho in oligodendrocytes may not only provide new insights into the development of myelin but also in the pathogenesis of myelin-related diseases.

\section{References}

Arantes RM, Andrews NW (2006) A role for synaptotagmin VII-regulated exocytosis of lysosomes in neurite outgrowth from primary sympathetic neurons. J Neurosci 26:4630-4637.

Bagatolli LA, Sanchez SA, Hazlett T, Gratton E (2003) Giant vesicles, Laurdan, and two-photon fluorescence microscopy: evidence of lipid lateral separation in bilayers. Methods Enzymol 360:481-500.

Barres BA, Raff MC (1999) Axonal control of oligodendrocyte development. J Cell Biol 147:1123-1128.

Bomsel M, Prydz K, Parton RG, Gruenberg J, Simons K (1989) Endocytosis in filter-grown Madin-Darby canine kidney cells. J Cell Biol 109:3243-3258.

Buttery PC, ffrench-Constant C (1999) Laminin-2/integrin interactions enhance myelin membrane formation by oligodendrocytes. Mol Cell Neurosci 14:199-212.

Cheng ZJ, Singh RD, Sharma DK, Holicky EL, Hanada K, Marks DL, Pagano RE (2006) Distinct mechanisms of clathrin-independent endocytosis have unique sphingolipid requirements. Mol Biol Cell 17:3197-3210.

Chun SJ, Rasband MN, Sidman RL, Habib AA, Vartanian T (2003) Integrinlinked kinase is required for laminin-2-induced oligodendrocyte cell spreading and CNS myelination. J Cell Biol 163:397-408.

Colognato H, Ramachandrappa S, Olsen IM, ffrench-Constant C (2004) In- 
tegrins direct Src family kinases to regulate distinct phases of oligodendrocyte development. J Cell Biol 167:365-375.

Damm EM, Pelkmans L, Kartenbeck J, Mezzacasa A, Kurzchalia T, Helenius A (2005) Clathrin- and caveolin-1-independent endocytosis: entry of simian virus 40 into cells devoid of caveolae. J Cell Biol 168:477-488.

Debruin LS, Harauz G (2007) White matter rafting-membrane microdomains in myelin. Neurochem Res 32:213-228.

del Pozo MA, Balasubramanian N, Alderson NB, Kiosses WB, Grande-Garcia A, Anderson RG, Schwartz MA (2005) Phospho-caveolin-1 mediates integrin-regulated membrane domain internalization. Nat Cell Biol 7:901-908.

Dubois-Dalcq M, Behar T, Hudson L, Lazzarini RA (1986) Emergence of three myelin proteins in oligodendrocytes cultured without neurons. J Cell Biol 102:384-392.

Dugas JC, Tai YC, Speed TP, Ngai J, Barres BA (2006) Functional genomic analysis of oligodendrocyte differentiation. J Neurosci 26:10967-10983.

Edgar JM, McLaughlin M, Yool D, Zhang SC, Fowler JH, Montague P, Barrie JA, McCulloch MC, Duncan ID, Garbern J, Nave KA, Griffiths IR (2004) Oligodendroglial modulation of fast axonal transport in a mouse model of hereditary spastic paraplegia. J Cell Biol 166:121-131.

Fernandez-Borja M, Janssen L, Verwoerd D, Hordijk P, Neefjes J (2005) RhoB regulates endosome transport by promoting actin assembly on endosomal membranes through Dia1. J Cell Sci 118:2661-2670.

Fitzner D, Schneider A, Kippert A, Mobius W, Willig KI, Hell SW, Bunt G, Gaus K, Simons M (2006) Myelin basic protein-dependent plasma membrane reorganization in the formation of myelin. EMBO J 25:5037-5048.

Fivaz M, Vilbois F, Thurnheer S, Pasquali C, Abrami L, Bickel PE, Parton RG, van der Goot FG (2002) Differential sorting and fate of endocytosed GPI-anchored proteins. EMBO J 21:3989-4000.

Gasman S, Kalaidzidis Y, Zerial M (2003) RhoD regulates endosome dynamics through Diaphanous-related Formin and Src tyrosine kinase. Nat Cell Biol 5:195-204.

Gatto CL, Walker BJ, Lambert S (2003) Local ERM activation and dynamic growth cones at Schwann cell tips implicated in efficient formation of nodes of Ranvier. J Cell Biol 162:489-498.

Gaus K, Gratton E, Kable EP, Jones AS, Gelissen I, Kritharides L, Jessup W (2003) Visualizing lipid structure and raft domains in living cells with two-photon microscopy. Proc Natl Acad Sci USA 100:15554-15559.

Gaus K, Le Lay S, Balasubramanian N, Schwartz MA (2006) Integrinmediated adhesion regulates membrane order. J Cell Biol 174:725-734.

Gielen E, Baron W, Vandeven M, Steels P, Hoekstra D, Ameloot M (2006) Rafts in oligodendrocytes: evidence and structure-function relationship. Glia 54:499-512.

Gudz TI, Schneider TE, Haas TA, Macklin WB (2002) Myelin proteolipid protein forms a complex with integrins and may participate in integrin receptor signaling in oligodendrocytes. J Neurosci 22:7398-7407.

Gudz TI, Komuro H, Macklin WB (2006) Glutamate stimulates oligodendrocyte progenitor migration mediated via an $\alpha \mathrm{v}$ integrin/myelin proteolipid protein complex. J Neurosci 26:2458-2466.

Jung M, Kramer E, Grzenkowski M, Tang K, Blakemore W, Aguzzi A, Khazaie K, Chlichlia K, von Blankenfeld G, Kettenmann H, et al (1995) Lines of murine oligodendroglial precursor cells immortalized by an activated neu tyrosine kinase show distinct degrees of interaction with axons in vitro and in vivo. Eur J Neurosci 7:1245-1265.

Jung M, Sommer I, Schachner M, Nave KA (1996) Monoclonal antibody O10 defines a conformationally sensitive cell-surface epitope of proteolipid protein (PLP): evidence that PLP misfolding underlies dysmyelination in mutant mice. J Neurosci 16:7920-7929.

Kirkham M, Fujita A, Chadda R, Nixon SJ, Kurzchalia TV, Sharma DK, Pagano RE, Hancock JF, Mayor S, Parton RG (2005) Ultrastructural identification of uncoated caveolin-independent early endocytic vehicles. J Cell Biol 168:465-476.

Kramer-Albers EM, Gehrig-Burger K, Thiele C, Trotter J, Nave KA (2006) Perturbed interactions of mutant proteolipid protein/DM20 with cholesterol and lipid rafts in oligodendroglia: implications for dysmyelination in spastic paraplegia. J Neurosci 26:11743-11752.

Lamaze C, Dujeancourt A, Baba T, Lo CG, Benmerah A, Dautry-Varsat A (2001) Interleukin 2 receptors and detergent-resistant membrane domains define a clathrin-independent endocytic pathway. Mol Cell 7:661-671.

Liang X, Draghi NA, Resh MD (2004) Signaling from integrins to Fyn to
Rho family GTPases regulates morphologic differentiation of oligodendrocytes. J Neurosci 24:7140-7149.

McLaughlin M, Barrie JA, Karim S, Montague P, Edgar JM, Kirkham D, Thomson CE, Griffiths IR (2006) Processing of PLP in a model of Pelizaeus-Merzbacher disease/SPG2 due to the rumpshaker mutation. Glia 53:715-722.

Melendez-Vasquez CV, Rios JC, Zanazzi G, Lambert S, Bretscher A, Salzer JL (2001) Nodes of Ranvier form in association with ezrin-radixin-moesin (ERM)-positive Schwann cell processes. Proc Natl Acad Sci USA 98:1235-1240.

Melendez-Vasquez CV, Einheber S, Salzer JL (2004) Rho kinase regulates Schwann cell myelination and formation of associated axonal domains. J Neurosci 24:3953-3963.

Mi S, Miller RH, Lee X, Scott ML, Shulag-Morskaya S, Shao Z, Chang J, Thill G, Levesque M, Zhang M, Hession C, Sah D, Trapp B, He Z, Jung V, McCoy JM, Pepinsky RB (2005) LINGO-1 negatively regulates myelination by oligodendrocytes. Nat Neurosci 8:745-751.

Milner RJ, Lai C, Nave KA, Lenoir D, Ogata J, Sutcliffe JG (1985) Nucleotide sequences of two mRNAs for rat brain myelin proteolipid protein. Cell 42:931-939.

Mirsky R, Winter J, Abney ER, Pruss RM, Gavrilovic J, Raff MC (1980) Myelin-specific proteins and glycolipids in rat Schwann cells and oligodendrocytes in culture. J Cell Biol 84:483-494.

Orlandi PA, Fishman PH (1998) Filipin-dependent inhibition of cholera toxin: evidence for toxin internalization and activation through caveolaelike domains. J Cell Biol 141:905-915.

Osterhout DJ, Wolven A, Wolf RM, Resh MD, Chao MV (1999) Morphological differentiation of oligodendrocytes requires activation of Fyn tyrosine kinase. J Cell Biol 145:1209-1218.

Pfeiffer SE, Warrington AE, Bansal R (1993) The oligodendrocyte and its many cellular processes. Trends Cell Biol 3:191-197.

Qualmann B, Mellor H (2003) Regulation of endocytic traffic by Rho GTPases. Biochem J 371:233-241.

Ren XD, Kiosses WB, Schwartz MA (1999) Regulation of the small GTPbinding protein Rho by cell adhesion and the cytoskeleton. EMBO J 18:578-585.

Ridley AJ (2006) Rho GTPases and actin dynamics in membrane protrusions and vesicle trafficking. Trends Cell Biol 16:522-529.

Robertson D, Paterson HF, Adamson P, Hall A, Monaghan P (1995) Ultrastructural localization of ras-related proteins using epitope-tagged plasmids. J Histochem Cytochem 43:471-480.

Sabharanjak S, Sharma P, Parton RG, Mayor S (2002) GPI-anchored proteins are delivered to recycling endosomes via a distinct cdc42-regulated, clathrin-independent pinocytic pathway. Dev Cell 2:411-423.

Salzer JL (2003) Polarized domains of myelinated axons. Neuron 40:297-318.

Sandilands E, Cans C, Fincham VJ, Brunton VG, Mellor H, Prendergast GC, Norman JC, Superti-Furga G, Frame MC (2004) RhoB and actin polymerization coordinate Src activation with endosome-mediated delivery to the membrane. Dev Cell 7:855-869.

Schafer DP, Rasband MN (2006) Glial regulation of the axonal membrane at nodes of Ranvier. Curr Opin Neurobiol 16:508-514.

Schmalzing G, Richter HP, Hansen A, Schwarz W, Just I, Aktories K (1995) Involvement of the GTP binding protein Rho in constitutive endocytosis in Xenopus laevis oocytes. J Cell Biol 130:1319-1332.

Schneider A, Lander H, Schulz G, Wolburg H, Nave KA, Schulz JB, Simons M (2005) Palmitoylation is a sorting determinant for transport to the myelin membrane. J Cell Sci 118:2415-2423.

Sherman DL, Brophy PJ (2005) Mechanisms of axon ensheathment and myelin growth. Nat Rev Neurosci 6:683-690.

Simons M, Trajkovic K (2006) Neuron-glia communication in the control of oligodendrocyte function and myelin biogenesis. J Cell Sci 119:4381-4389.

Simons M, Kramer EM, Thiele C, Stoffel W, Trotter J (2000) Assembly of myelin by association of proteolipid protein with cholesterol- and galactosylceramide-rich membrane domains. J Cell Biol 151:143-154.

Simons M, Kramer EM, Macchi P, Rathke-Hartlieb S, Trotter J, Nave KA, Schulz JB (2002) Overexpression of the myelin proteolipid protein leads to accumulation of cholesterol and proteolipid protein in endosomes/ lysosomes: implications for Pelizaeus-Merzbacher disease. J Cell Biol 157:327-336.

Siskova Z, Baron W, de Vries H, Hoekstra D (2006) Fibronectin impedes 
"myelin" sheet-directed flow in oligodendrocytes: a role for a beta 1 integrin-mediated PKC signaling pathway in vesicular trafficking. Mol Cell Neurosci 33:150-159.

Taylor CM, Marta CB, Claycomb RJ, Han DK, Rasband MN, Coetzee T, Pfeiffer SE (2004) Proteomic mapping provides powerful insights into functional myelin biology. Proc Natl Acad Sci USA 101:4643-4648.

Thurnherr T, Benninger Y, Wu X, Chrostek A, Krause SM, Nave KA, Franklin RJ, Brakebusch C, Suter U, Relvas JB (2006) Cdc42 and Rac1 signaling are both required for and act synergistically in the correct formation of myelin sheaths in the CNS. J Neurosci 26:10110-10119.

Trajkovic K, Dhaunchak AS, Goncalves JT, Wenzel D, Schneider A, Bunt G, Nave KA, Simons M (2006) Neuron to glia signaling triggers myelin membrane exocytosis from endosomal storage sites. J Cell Biol 172:937-948.

Wherlock M, Gampel A, Futter C, Mellor H (2004) Farnesyltransferase in- hibitors disrupt EGF receptor traffic through modulation of the RhoB GTPase. J Cell Sci 117:3221-3231.

Wolf RM, Wilkes JJ, Chao MV, Resh MD (2001) Tyrosine phosphorylation of p190 RhoGAP by Fyn regulates oligodendrocyte differentiation. J Neurobiol 49:62-78.

Wubbolts R, Fernandez-Borja M, Oomen L, Verwoerd D, Janssen H, Calafat J, Tulp A, Dusseljee S, Neefjes J (1996) Direct vesicular transport of MHC class II molecules from lysosomal structures to the cell surface. J Cell Biol 135:611-622.

Yiu G, He Z (2006) Glial inhibition of CNS axon regeneration. Nat Rev Neurosci 7:617-627.

Yoshizaki H, Ohba Y, Kurokawa K, Itoh RE, Nakamura T, Mochizuki N, Nagashima K, Matsuda M (2003) Activity of Rho-family GTPases during cell division as visualized with FRET-based probes. J Cell Biol 162: 223-232. 